Canadian University Music Review

Canadian University Music Review

Revue de musique des universités canadiennes

\title{
From Point to Sphere: Spatial Organization of Sound in Contemporary Music (after 1950)
}

\section{Maria Harley}

Numéro 13, 1993

URI : https://id.erudit.org/iderudit/1014300ar

DOI : https://doi.org/10.7202/1014300ar

Aller au sommaire du numéro

\section{Éditeur(s)}

Canadian University Music Society / Société de musique des universités canadiennes

\section{ISSN}

0710-0353 (imprimé)

2291-2436 (numérique)

Découvrir la revue

Citer cet article

Harley, M. (1993). From Point to Sphere: Spatial Organization of Sound in Contemporary Music (after 1950). Canadian University Music Review / Revue de musique des universités canadiennes, (13), 123-144.

https://doi.org/10.7202/1014300ar

\section{Résumé de l'article}

In this study of spatial organization of sound, that is of "spatialization" in music, the term "spatial" refers to the three-dimensional performance space, not to pitch. "Spatialized music," distinct both from polychoral music and from musical theatre, means music with quasi-spatial structure defined by the composer in the score or in another medium of sound coding (digital or analog recording, specific software). Spatialization includes ensemble dispersion, movement of sounds, performers and audience, juxtaposition and interaction of real and virtual sound sources - every situation in which the position of the sound sources and the acoustic quality of the performance space are given compositional significance. A classification of spatial designs in music is followed by examples illustrating three aspects of spatialization: (1) the expression or simulation of geometrical patterns in music, (2) the movement of sound, (3) the symbolic function of spatial designs and movement. Musical examples and graphs of performer placement are taken from Henry Brant's Millenium II (1954), Karlheinz Stockhausen's Gruppen für drei Orchester (1955-57), Iannis Xenakis's Terrêtektorh (1965-66) and John Tavener's Ultimos Ritos (1972).
All Rights Reserved (C Canadian University Music Society / Société de musique des universités canadiennes, 1993
Ce document est protégé par la loi sur le droit d'auteur. L'utilisation des services d'Érudit (y compris la reproduction) est assujettie à sa politique d'utilisation que vous pouvez consulter en ligne.

https://apropos.erudit.org/fr/usagers/politique-dutilisation/ 


\title{
FROM POINT TO SPHERE: SPATIAL ORGANIZATION OF SOUND IN CONTEMPORARY MUSIC (AFTER 1950)
}

\author{
Maria Harley
}

\section{Point of Departure}

Space is experienced in time, time in space: in human experience there is no absolute space existing without time nor time without space. In thinking about music, however, time has often been assigned an unquestionable primacy. In the words of Igor Stravinsky, "the phenomenon of music is given to us with the sole purpose of establishing order in things, including, and particularly, the coordination between man and time." 1 Not between man and space: this is the domain of the visual arts.

Yet sound, the substance of music, is inherently spatial. ${ }^{2}$ Composers have rediscovered the spatial aspects of sound in the second half of the twentieth century. The position, movement, extension and context of sound have been included amongst the elements of music endowed with compositional significance. ${ }^{3}$ The list of composers involved with this "spatialization" of music is rather lengthy: Henry Brant, Pierre Boulez, Luciano Berio, John Cage, Elliott Carter, John Chowning, Francis Dhomont, Ton de Leeuw, Brian Ferneyhough, Peter Maxwell Davies, Bruno Maderna, Krzysztof Penderecki, R. Murray Schafer, Kazimierz Serocki, Karlheinz Stockhausen, John Tavener, Iannis Xenakis, Bernd Alois Zimmerman, and many others. Few of these composers

1 Igor Stravinsky, An Autobiography (New York: W. W. Norton \& Co., 1962 (first edition New York: Simon and Schuster, Inc., 1936), 54.

2 Jens Blauert considers the expression "spatial hearing" to be a tautology; hearing is always spatial because of the nature of the human auditory system (Spatial Hearing: the Psychophysics of Human Sound Localization, trans. John S. Allen (Cambridge: MIT Press, 1983), 3.

3 Important predecessors of modern techniques of spatialization include composers of polychoral music in the late renaissance and early baroque eras, as well as Hector Berlioz, Gustav Mahler, and Charles Ives. See E. C. Bass, "Musical Time and Space in Berlioz." The Music Review 30, no. 3 (1969): 211-24; Nadine Sine, The Evolution of Symphonic Worlds: Tonality in the Symphonies of Gustav Mahler, with Emphasis on the First, Third, and Fifth (Ph. D. diss., New York University, 1983); and Robert P. Morgan, "Spatial Form in Ives." An Ives Celebration: Papers and Panels of the Charles Ives Centennial Festival-Conference (Chicago: University of Illinois Press, 1974), 145-158. 
limit their interest exclusively to spatialized music as Henry Brant has done. ${ }^{4}$ The majority use the various aspects of the spatiality of sound within the constraints of individual works; the techniques of ensemble dispersion or sound movement, for instance, are merely two of the available compositional options.

Here, an important terminological clarification is needed: the term "spatial" relates to the physical, three-dimensional space, or its enclosed fragments within which the music is performed, and not to the abstract realm of pitch space or its derivatives. ${ }^{5}$ The transformation "from point to sphere" refers, then, to a changing understanding of music from the purely temporal and non-spatial to the fully spatio-temporal. The first idea is symbolized by the image of the point. It has no volume, it is bodiless; the spatiality of music is irrelevant. The sphere symbolizes the opposite. Music is perceived in the entirety of its spatio-temporal presence surrounding the listeners with a multi-directional pattern of sounds. ${ }^{6}$

This article focuses on the latter end of such a "point-to- sphere" conceptual trajectory. An attempt to define spatialization and to classify spatial scenarios used in works composed after 1950 will be followed with discussions of selected compositions. These works exemplify three aspects of spatialization in instrumental music: (1) the expression or simulation of spatial images and forms (i.e. geometric patterns) in music, (2) the movement of sound, (3) the symbolic function of spatialization. These categories are often intertwined; works with varied and unusual placements of performers may include apparent sound movement, and may have a symbolic content. The order of the presentation of musical examples will, again, follow the direction from point to sphere, from one to three-dimensional patterns of performer placement.

\section{General Considerations}

From the phenomenological point of view, Western art music is unique in that its predominant mode of existence is through distinct musical works, or compositions, each in the form of an abstract model (the score) brought to life in

4 Dorothy Carter Drennan, Relationship of Ensemble Dispersion to Structure in the Music of Henry Brant, Ph. D. dissertation (University of Miami, 1975.

5 Among theoretical and musicological studies of pitch-related spaces, the contributions of Robert D. Morris (Composition with Pitch Classes: A Theory of Compositional Design [New Haven: Yale University Press, 1987]) and Marie-Elisabeth Duchez ("La représentation spatio-verticale du caractère musical grave-aigu et l'élaboration de la notion de hauteur de son dans la conscience musicale occidentale," Acta Musicologica 1 [(1979], 54-73) are particularly important.

6 The image of the sphere is an idealization implying a stationary audience within a spherical enclosure, or a single listener limited by his or her hearing range (see Don Ihde, Listening and Voice: A Phenomenology of Sound [Athens, Ohio: Ohio U. Press, 1976]). 
concrete, sonorous, spatio-temporal realizations through various performances. ${ }^{7}$ Thinking of music in terms of individual, separate and unique compositions is radically different from thinking of it in terms of the process of sound-making, or in terms of a social activity. The musical work is seen here as a special type of object supplied with a material basis of existence by the musical notation contained in the score. The musical "object" has a fixed quasi-temporal structure, ${ }^{8}$ a structure which is quasi-temporal because temporal relationships encoded in the score are approximated in a different way in each performance.

By extending Ingarden's terminology, it is possible to speak of a fixed quasispatial structure in music. This structure is indicated by the instrumentation which usually assumes certain acoustical conditions for the performance (for example, a background of silence and an appropriate size and quality of performance space) as well as standards of performer placement (for example, soloists and groups centred on the stage, facing the audience). The relational character of the quasi-temporal and quasi-spatial aspects of the musical work becomes more apparent when thinking about the identity of various, widely divergent interpretative readings. It is not the physically spatial and temporal features that are preserved from one performance to the next, but their schematic outlines fixed in the musical notation.

Apparently, music for one instrument, such as the piano, has no quasi-spatial structure and seems to be neutral from the spatial point of view. Spatially speaking, there is no difference between a Prélude by Debussy and one by Chopin, if both are performed on the same instrument in the same concert hall and if the dynamic levels are similar (timbre and dynamics are linked to the spatial qualities of sound). ${ }^{9}$ Obviously, a standard placement of audience and performer is assumed; we should not forget that in certain works the instrumentalist may wander around the concert hall or the audience around the instrumentalist. In these circumstances the structure of the work is quasi-spatial.

Chamber and orchestral music has a quasi-spatial structure when the seating plan given by the composer differs from the conventional one, when the audience or the performers are required to move, and when there are several various ensembles of performers dispersed in the hall or on the stage. Conversely,

7 Roman Ingarden, The Work of Music and the Problem of its Identity, transl. Adam Czerniawski (Berkeley: University of California Press, 1986). Jean-Jacques Nattiez, Music and Discourse. Toward a Semiology of Music, transl. Carolyn Abbate (Princeton, New Jersey: Princeton University Press, 1990.

8 The term is Ingarden's; see footnote 7.

9 Jens Blauert, Spatial Hearing. The Psychophysics of Human Sound Localization, transl. John S. Allen (Cambridge: MIT Press, 1983), and Albert S. Bregman, Auditory Scene Analysis: The Perceptual Organization of Sound (Cambridge, Mass.: MIT Press, 1990). 
chamber and orchestral music has a latent quasi-spatial structure when the ensemble placement is standard, well-known and does not have to be specified. Most of the music composed for specific instrumental groups takes for granted certain types of spatial relationships inherent in the kind and size of the ensemble. The distinction between chamber and symphonic music, for instance, implies musical differences resulting from the various number of performers and the nature of the interactions of instrumental sounds with the acoustic properties of the concert hall. Anton von Webern once mentioned the size of the concert hall as a part of the concept of the composition, writing to Schoenberg about his Pieces for Orchestra op. 10 (on 6 July 1910):

\footnotetext{
There will be a number of short pieces that I shall call chamber pieces for orchestra in order to indicate that they should not be played in a large hall. Until now the instrumentation has been very small - a fact that gave me this idea ... In a large hall one would hardly be able to hear anything of the music. ${ }^{10}$
}

Spatial relationships of positions of and distances between various instruments and groups, the necessity of balancing their sonorities, the influence of the acoustic properties of concert halls on the perceived sounds of voices and instruments - all these existed before spatialization techniques as such and were taken into account in instrumentation. It is not surprising that Berlioz, author of the Traité d' instrumentation et d' orchestration modernes (Berlioz 1844) is also one of the important predecessors of modern spatialization (as for example, the Requiem op. 5).

\section{Towards a Definition}

There are several difficulties in proposing a clear definition of the musical phenomenon of spatialization. The distinction between works with quasi-spatial structure (unusual seating plans, movement, ensemble dispersion) and latent quasi-spatial structure (standard seating plans) proposed above may be a source of concern. If what is latently spatial can be termed "spatialized," the definition is too inclusive. Spatialization relates to compositions in which the orchestra is split into separate ensembles; nevertheless it suffices to have a large number of divisi parts to obtain a spatially extended sonority, varied within the confines of the stage (for example, in Xenakis's Pithoprakta for orchestra, 1958). In this

10 Hans Moldenhauer, Anton von Webern: A Chronicle of His Life and Work (London: Gollancz, 1978), 194-95, quoted by permission of the copyright holder. 
case, spatialization does not relate to the measurable aspects of the performance space (distances, angles, symmetries), but rather it is expressed through internal, microscopic differentiation in the orchestral sonorities. In other words, space is linked to texture, a tactile, and again, spatial entity. ${ }^{11}$ This aspect of spatialization should not be excluded from the definition.

Another difficulty in defining spatialization stems from the difference between this phenomenon and traditional "polychorality." Polychoral music involves more than one choir or ensemble without specifying its spatial position in the performance space. ${ }^{12}$ Spatial aspects of such works are limited to the division of the performers into separated ensembles; this distinctness implies only unspecified distance, not direction. At the same time, the musical interactions of these separate groups can be quite sophisticated.

The label of polychorality can be attached to those twentieth-century works that include a number of ensembles placed separately on the stage. These, usually large, ensembles either are without a specific placement plan (as in Krzysztof Penderecki's monumental compositions, including the St. Luke Passion of 1965), or are given several (two or three) optional positions on the stage (as in Elliott Carter's A Symphony of Three Orchestras of 1976 with two possible placements of the three orchestras). Here, important spatial features of sound (direction, distance) have no significance. What matters is that a degree of separation is provided by the distance between the various groups of performers.

Finally, the distinction between spatialized music and musical theatre needs to be clarified. Reinhard J. Sacher maintains that all spatialization of music is essentially theatrical. ${ }^{13} \mathrm{He}$ argues that when the performers surround the

11 In a conversation with Célestin Deliège, Pierre Boulez criticized the traditional set-up of the orchestra subdivided into a series of homogeneous groups ("screens"). He proposed to split these homogeneous ensembles in order to create a new fusion of orchestral sonorities through the alternation of the placement of instruments on the stage (Pierre Boulez, Conversations with Célestin Deliège [London: Ernst Eulenburg Ltd, 1976], 100). This idea is realized in Figures, Doubles, Prismes (1963-1966) where, through a change of the orchestral seating plan, the music gains a greater degree of internal, textural articulation.

12 Anthony F. Carver gives the following definition of the term polychoral as applied to sixteenthcentury music: "A polychoral work or passage is one in which the ensemble is consistently split into two or more groups, each retaining its own identity, which sing separately and together within a through-composed framework in which antiphony is a fundamental compositional resource" (Cori Spezzati [I: The Development of Sacred Polychoral Music to the Time of Schütz; II: An Anthology of Sacred Polychoral Music], Cambridge: Cambridge U. Press, 1988).

13 Reinhard Josef Sacher, Musik als Theater. Zur Entstehungsgeschichte des Instrumentalen Theaters (Ph. D. diss., Cologne, 1985); see also the same author's "Musik als Theater. Tendenzen zur Grenzüberschreitung in der Musik von 1958 bis 1968," Kölner Beitrage zur Musikforschung (Regensburg: Klaus Wolfgang Niemöller, 1985. 
audience, visual cues tend to dominate over their aural counterparts. This is, however, a matter of the voluntary focus of attention by the listener/viewer: a conventional concert may be also perceived as a form of $(\mathrm{bad})$ theatre. Spatialized music and musical theatre are distinct: all theatre is spatial but not necessarily spatialized, and not all spatialization is theatrical.

The term "spatialized music" refers, then, to music with a quasi-spatial structure defined by the composer in the score or in another medium of sound coding (digital or analog recording, specific software). This quasi-spatial structure can assume different forms, including ensemble dispersion specified in the score, the movement of sounds, performers and the audience, and the juxtaposition and interaction of real and virtual sound sources. The presence of the technique of spatialization can be recognized in every situation in which the position (direction and distance) of the sound sources and the acoustic quality of the performance space are given compositional importance.

In his influential article on music in space, Karlheinz Stockhausen postulated the adoption of spatial direction, easily serialized, as the new 'parameter' of musical sound. ${ }^{14}$ This is hardly the sole possibility, but an important starting point for a new, non-polychoral usage of the spatial properties of sound in music.

\section{Classifications}

From the acoustic point of view, one can distinguish three types of sound-space: (a) real sound sources (voices or instruments), (b) virtual sound sources (loudspeakers), and (c) a mixture of both. In all three kinds of sound-space, similar spatial effects can emerge. The most important of these effects - which could be almost called the "emblematic" idea of spatial organization - is the imitation of continuous sound movement in space by using discrete sources, such as four or six orchestral groups or loudspeakers surrounding the audience. Spatial designs from all three sound-space types can be endowed with symbolic significance. The compositional use of a spatial distribution may be inspired by geographic or architectural shapes as well as by the intent to portray or evoke mythical, ritual or imaginary spaces.

Depending on the kind of configuration of static or mobile performers and static or mobile audience, a different classification of spatialized compositions may be proposed. The first category of static performers and audience is undoubtably the most common, but mobile performers (category II) and mobile audiences (category III) are also possible.

14 Karlheinz Stockhausen, "Musik im Raum" in Die Reihe 5 (1959); trans. Ruth Koenig as "Music in Space" in Die Reihe 5 (1961): 67-82. 
In instrumental and vocal-instrumental music (sound-space type a), the classification of spatialized works can follow the number of groups utilized or can be related to the geometrical layout of the musicians and the position of the audience. The latter option reveals more features of the spatialization and will be applied here. The spatial geometry of music realized within the confines of the concert hall can assume the well-known regular forms of a line-segment, triangle, square, hexagon, or circle. The patterns of performer placement may also be irregular. Thus, the main subdivisions within the first category of stationary performers and the audience are: (a) from two to several individual ensembles on the stage; (b) two opposed ensembles in dialogue or antiphony (between the two sides of the hall or on its front-back axis); (c) three to several groups placed symmetrically around the audience (the audience is surrounded by music); (d) a stochastic mixture of orchestra and the public on one spatial plane (the audience is 'inside' music); and (e) several groups dispersed in various patterns on the stage, around and in between the audience, and at various levels within the whole three-dimensional performance space.

All these arrangements may be further enriched by the inclusion of the movement of the musicians (category II). Several kinds of motion may be distinguished: (a) movement within the concert hall on the stage (performers' axial rotations and changes of prescribed positions, that is, from one music-stand to another), (b) movement onto and off the stage, around and outside the concert hall, (c) movement within the area of an unconventional performance space (for example, a Berlin park for Stockhausen's Sternklang of 1971). The seemingly infinite wealth of possibilities opened up here is limited by the theatrical character of the performer's movement in music. When the importance of the musicians' actions overshadows that of the sonorous results of these actions, music becomes theatre.

The movement of the audience forms a separate category of spatialization (no. III), a category rarely employed in the concert hall. The noisy informality of mobile listeners is more suitable for experimental music in which all conventions and limits are being contested. Works in open form, for instance, have utilized ensemble dispersion in separate rooms of a house or other spatial locations. Various conceptual compositions have included the idea of giving an audience the task of exploring certain defined acoustic spaces.

In the area of electroacoustic music (sound-space type b), static and mobile aspects of sound are interrelated. Virtual sound sources are not tied to the location of their carriers (loudspeakers). Here, all aspects of sound have to be planned in advance and created directly, including the spatial positions, extensions, and movements of sound objects, as well as the quality of simulated spaces (apparent size, reverberation time and timbre, resonances, echoes). This method of 
composing is radically different from that of writing out a score which indicates the instruments and includes an imprecise specification of their timbres and dynamics as well as a schema of locations. In most instrumental music the acoustic quality of the performance space lies beyond the control of the composer unless, as in category III, he decides to take his audience on a listening tour through various sonorous environments. Even then the listeners are only visiting different, static "spaces."

The classification of spatial patterns in electroacoustic music relates to the material basis for the stationary and moving sound images, that is to various configurations of loudspeakers. The possible arrangements include: (a) one point source (images of different depth); (b) stereophony (two loudspeakers creating a continuous, virtual two-dimensional sound image in front of the listener); (c) quadrophony (four loudspeakers at the corners of the performance space around the audience, the shape and extension of the auditory image being disputable); (d) multi-loudspeaker projection systems using point sources, or (e) multi-loudspeakers systems based on stereo pairs in various configurations (both categories can be labelled orchestras of loudspeakers and may be used in a variety of projection spaces); and (f) moving loudspeakers (e.g. experimental sound sculptures).

For electroacoustic music spatiality is a condition sine qua non. This was already apparent in the early musique concrète experiments of Pierre Schaeffer and Pierre Henry presented at their concerts in Paris in 1951 to $1952 .{ }^{15}$ An abundance of new spatial phenomena have emerged throughout the history of electronic music, from synthetic, non-spatial sounds, through multi-layered and mobile sound images to variable spaces. ${ }^{16}$ The introduction of computers has enabled composers to refine their techniques and introduce new effects. ${ }^{17}$

15 Paradoxically, musique concrète, by having influenced the spatial ideas of Stockhausen, constitutes an important stage in the development of the technique of spatialization in instrumental music.

16 Kurt Blaukopf, "Space in Electronic Music," Music and Technology [papers from the UNESCO conference held in Stockholm (June, 1970)], in La Revue Musicale, (Paris: 1971), 157-72.

17 For instance, a simulation of moving sound sources in four-channel systems has been developed by John Chowning ("The Simulation of Moving Sound Sources," a paper presented at the ThirtyEighth Convention of the Audio-Engineering Society, 4-7 May 1970, preprint no. 726. Reprinted in Computer Music Journal 1:3 [June, 1977], 48-52). In this program, the apparent position and movement of the sound in a virtual acoustic space is controlled by the distribution of direct and reverberant signals between the loudspeakers to provide the angular and distance information, and by using the Doppler shift for velocity information. The program was first utilized by Chowning in Turenas (1972). For a comprehensive discussion of spatial manipulation and computers, see Durand R. Begault, "Spatial Manipulation and Computers: A Tutorial for Composers," Ex Tempore: AJournal of Compositional and Theoretical Research in Music 4, no. 1 (Spring-Summer, 1986), 56-88. 
The approximation of a circle with four sound sources, an effect attempted in both acoustic and electroacoustic music seems to be realized more successfully with the loudspeakers. In both cases, however, the illusions of sound movement and circularity work well only for listeners located in a limited area in the centre, equidistant from the four sound sources. Sound rotation can be more realistic when the number of groups or loudspeakers surrounding the audience is increased to six. ${ }^{18}$ In this configuration, the gaps in the circumference of the sound projection area are significantly diminished.

All electroacoustic categories of spatialization can be linked to those of vocalinstrumental music (type $\mathbf{c}$ of the general classification). The most common arrangement is that of a solo instrument with a stereo or quadrophonic sound projection system. This configuration transcends the limitations of its constituent elements (the disembodied quality of the sound from the loudspeakers and the constraints of a solo performance, especially that involving a monophonic instrument).

The configurations listed above refer to the number, type and positions of sound sources. Only in categories II and III (the movement of the performers and the audience) has the acoustic quality of the performance space been taken into account. The quality of the space is also significant in the case of many unconventional seating plans (especially within a square or a circle) or other unusual spatial conditions for the musical performance. These arrangements may require the abandonment of a traditional, rectangular concert hall for the sake of more variable performance spaces.

The discovery, invention and realization of new performance spaces is often linked to the reflection on the music's inherent spatiality. For Léo Kupper, creator of several multi-channel sound cupolas, "space is not an effect of the pitch dimension, but a parameter more important than pitch or rhythm and timbre articulations in music." ${ }^{19}$ Few composers share this radical view; its emergence, though, is symptomatic of the increasing importance of spatial organization in music.

\section{Examples of Spatial Organization of Sound}

The compositional use of a spatial distribution of instrumental ensembles (category la-e) will be exemplified below with works differing in design, scope

18 Blauert, Spatial Hearing, 273.

19 Léo Kupper, "Space Perception in the Computer Age," L'Espace du Son I (1988): 61. A sound cupola is a semi-spherical multi-loudspeaker sound projection system which may be installed in a gallery, church, or auditorium of appropriate size and dimensions. 
and quality. Attention will be given to the compositional, perceptual and symbolic aspects of spatialization.

When several instrumental groups are placed on the stage (category Ia) the effects, although limited to the same segment of space in front of the listeners, may be quite varied. Spatialization clarifies the multi-layered texture in Pierre Boulez's Rituel in memoriam Bruno Maderna (1975) in which eight groups of different size and timbre are seated according to a precise plan. The requirements of balance and symmetry are here linked to those of acoustics: the brass are placed at the back of the stage in order to not overpower the remaining instruments. In some cases, the subdivision of the orchestra on the stage is only a substitute for the planned and abandoned idea of ensemble dispersion in the hall (Elliott Carter's Concerto for Orchestra, 1970). Many independent layers may be juxtaposed in a collage, as in Zygmunt Krauze's Folk Music for orchestra (1972) with twenty-one groups performing different folk melodies simultaneously. The complex texture of this work becomes intelligible through its spatial extension on the stage.

In Brian Ferneyhough's Transit (1975) for six solo voices and chamber orchestra sitting in four semi-circles on the stage, the division and placement of orchestral instruments represent the four spheres depicted on the Renaissance woodcut which inspired this work. From the front of the stage to its back, the instruments symbolize the normal human world (woodwinds, voices), the stars (high percussion, harps), intermediary darkness (the strings), and finally the music of the spheres (brass). The coupling of symbolic and standard acoustical considerations is quite interesting: brass, the loudest group of instruments, is seated traditionally, at the back of the orchestra.

Two identical string orchestras (category Ib) placed as far as possible in Toru Takemitsu's The Dorian Horizon (1965) indicate a geometric model of a single line-segment with accented end-poles, and a musical model of a dialogue or antiphony. In Iannis Xenakis's Duel (1959/1960) and Strategie (1962) two orchestras with two conductors are involved in a mathematical game. This compositional design requires wide spatial separation of the participants of the game, but nothing more.

Three groups (Ic) form an equilateral triangle around the audience in Iannis Xenakis's Alax for three identical ensembles (1985). This arrangement enhances, through spatial separation, the perception of simultaneous layers of sound. It also allows the creation of spatial canons, echoes and overlapping sonorities as well as approximate imitations of sound movement.

One of the most influential compositions in the history of spatialized music, Gruppen für drei Orchester (1955-1957) by Karlheinz Stockhausen, calls for a massive force of 109 musicians (category Ic). These are split into three orchestras 

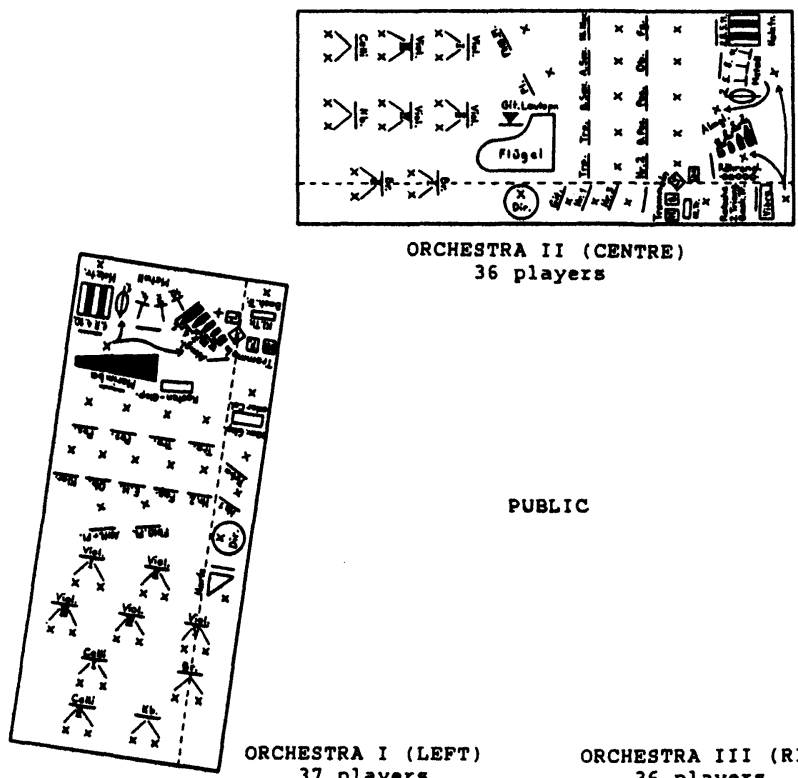

PUBLIC

37 players

ORCHESTRA III (RIGHT)

36 players

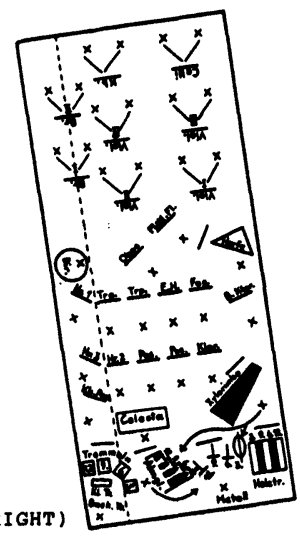

Example 1: The placement of the three orchestras in Stockhausen's Gruppen.

(C) 1963 by Universal Edition (London), Ltd., London. All rights reserved. Used by permission of European American Music Distributors Corporation, sole U.S. and Canadian agent for Universal Edition London.

(each with its own conductor) arranged in a horseshoe position on platforms semi-surrounding the audience in a large hall (example 1). In Stockhausen's words,

The similarity of the scoring of the three orchestras resulted from the requirement that sound-groups should be made to wander in space from one sounding body to another and at the same time split up similar soundstructures: each orchestra was supposed to call to the others and to give answer or echo. ${ }^{20}$

20 Stockhausen, Texte, v. 1, p. 156 (English translation by Ruth Koenig, 1961), 70. "Die Ähnlichkeit der 3 Orchesterbesetzungen ergab sich aus der Forderung, Tongrupper im Raum von einem Klangkörper zum anderen wandern zu lassen, gleichzeitig einander ähnliche Klangstrukturen aufzuteilen; jedes Orchester sollte den anderen zurufen, Antwort oder Echo geben können." 


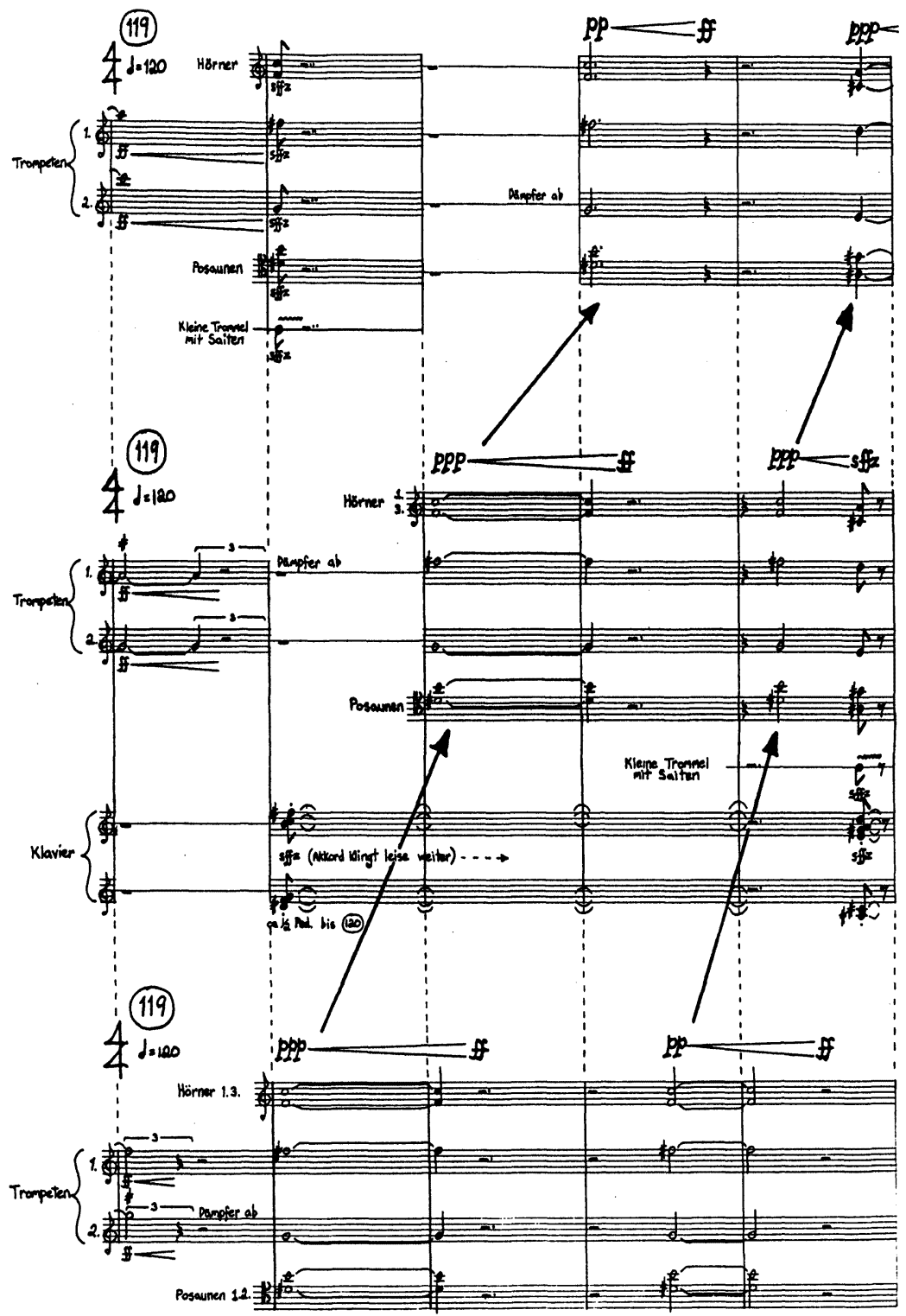

Example 2: The illusion of sound movement in Gruppen, group 119.

(C) 1963 by Universal Edition (London), Ltd., London. All rights reserved. Used by permission of European American Music Distributors Corporation, sole U.S. and Canadian agent for Universal Edition London. 
For the composer, it is important "to be able to experience the simultaneity of various time-spaces and movements" in this work. ${ }^{21}$ An instance of sound movement is presented at group 119 in the score with the rotation of three successive hexachords in the brass. The illusion of movement is constructed by a temporal overlapping and dynamic shaping of the sounds (example 2). The chords swell dynamically in the third, the second, and finally in the first orchestral group, creating an impression of the continuation of the sound essential for the perception of its movement. This simulation of motion by using stationary sources is not entirely successful: there are too few instrumental groups which are too distant in space and which play chords with the dynamic peaks too widely spaced in time. This, and the fact that brass timbres are quite difficult to match exactly, hampers the perception of a single auditory stream, that is, the image of a rotating sound. 22

Four groups are a better option for surrounding the audience with sound (continuation of category Ic). The groups can be placed in the corners of the hall or at middle points of the sides of the square, as in Stockhausen's Carré for four orchestras and choirs with four conductors (1959/1960). Here, voices and instruments are integrated into one static sound world, realizing the composer's wish that "this music should give a little inner stillness, breath and concentration." ${ }^{23}$ In Stockhausen's Carré and other works for four groups or loudspeakers around the audience the idea of surrounding the listeners with a static mass of sound constitutes an integral part of the composition. Quite often this idea also includes quasi-mystical overtones, serving to evoke other-worldly stillness and to induce a state of contemplation. The second part of R. Murray Schafer's Apocalypsis, entitled Credo (1978) and scored for twelve mixed choirs around the audience can be characterized in these terms.

Numerous moments of sound rotation in Carré reflect Stockhausen's contemporaneous preoccupation with sound movement. ${ }^{24}$ In Kontakte (1960), rotations were supplemented with various pointillistic patterns as well as with the effect of the "flood sound." This effect has been defined by Harvey as "a sound coming from one then successively from other loudspeakers thus gradually filling up the hall."25

Henry Brant had earlier noticed this effect in instrumental music: sounds of the same timbre when played continuously by an increasing number of performers

21 Stockhausen, Texte, v. 1, 71 .

22 The term "auditory stream" is taken from Bregman, Auditory Scene Analysis. (1990).

23 Karlheinz Stockhausen, Texte, vol. 2 (Cologne: Verlag M. DuMont Schauberg, 1964), 103.

24 Jonathan Harvey, The Music of Stockhausen. An Introduction by Jonathan Harvey (Berkeley and Los Angeles: University of California Press, 1975), 86-88.

25 Ibid., 88. 


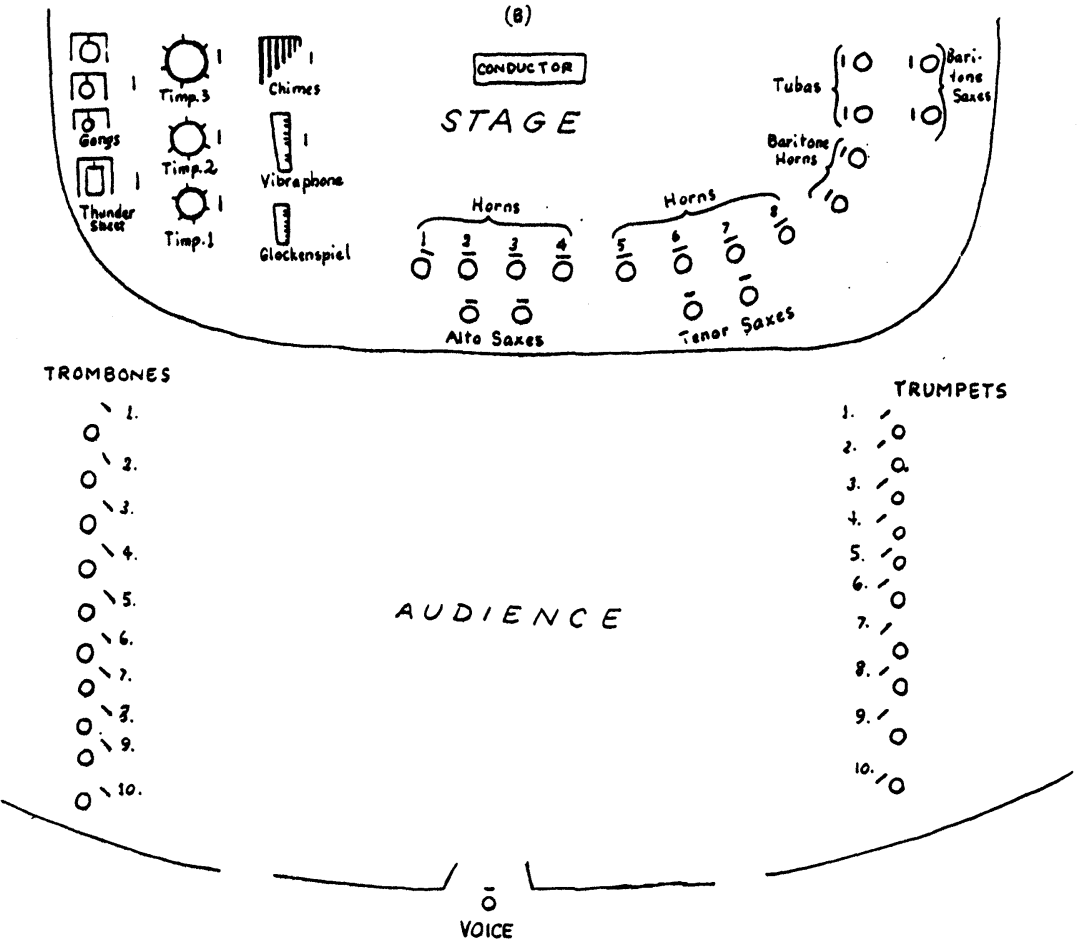

Example 3: Arrangement of the instruments in Henry Brant's Millenium II (1954).

(C) 1978 by Carl Fisher, Inc., New York. International copyright secured. Used by permission.

placed, for example along the walls of the hall, gradually fill up the hall. ${ }^{26}$ Dorothy Drennan termed this phenomenon in Brant's music "cumulative polyphony" and pointed out its presence in Millenium II (1954) and Voyage Four (1963), one of the most extravagant spatial compositions, calling for the placement of various instruments below the floor, on the stage, in the audience and on three balconies (category Ie). ${ }^{27}$ In Millenium II, a "spatial assembly" which predates Stockhausen's spatialized compositions,

26 Henry Brant, "Space as an Essential Aspect of Musical Composition," in Contemporary Composers on Contemporary Music, Elliott Schwartz and Barney Childs, eds. (New York: Holt, Rinehart and Winston, 1967).

27 Cf. Dorothy Carter Drennan, "Henry Brant's Use of Ensemble Dispersion," Music Review 38:1 (February, 1977): 65-68. 


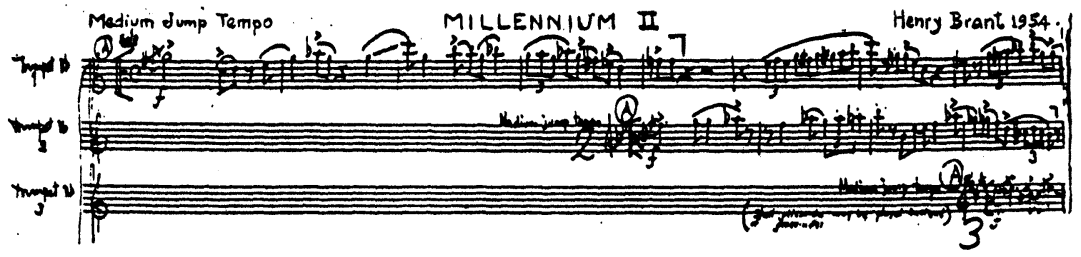

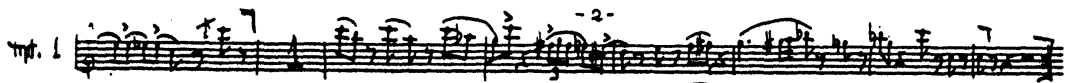

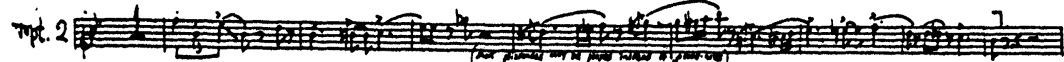

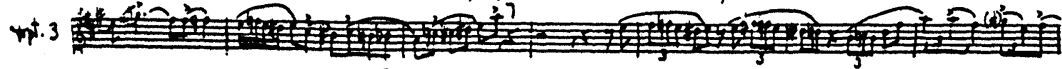

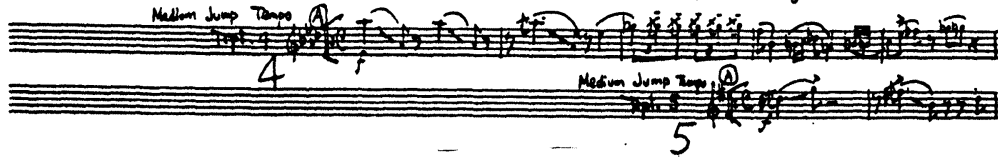
$-3$.

Tpt.1 H

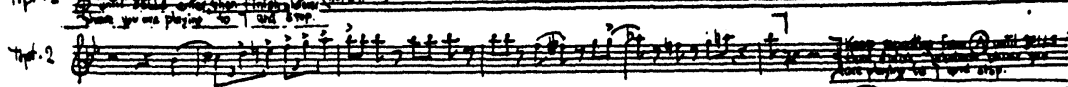

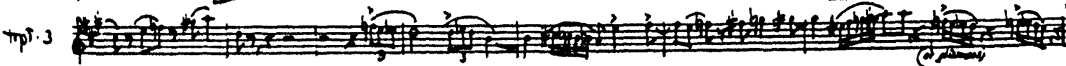
r.4

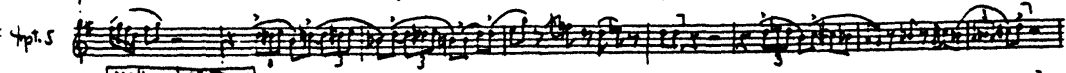
W

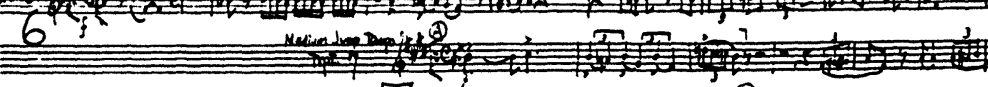
$\Longrightarrow$

Example 4: Entries of Trumpets 1-8 in Millenium II (pp. 1-3).

(C) 1978 by Carl Fisher, Inc., New York. International copyright secured. Used by permission.

Trumpets are spaced along one wall and trombones along the opposite wall ... The trumpets, followed by the trombones, begin playing one at a time, in the order of their placement along the walls. Each has a different melody in a different key and they continue to play until all have entered. Sound appears to travel down one wall and up the other. The centre area becomes progressively saturated and the hall appears to be filling up with sound. ${ }^{28}$ 


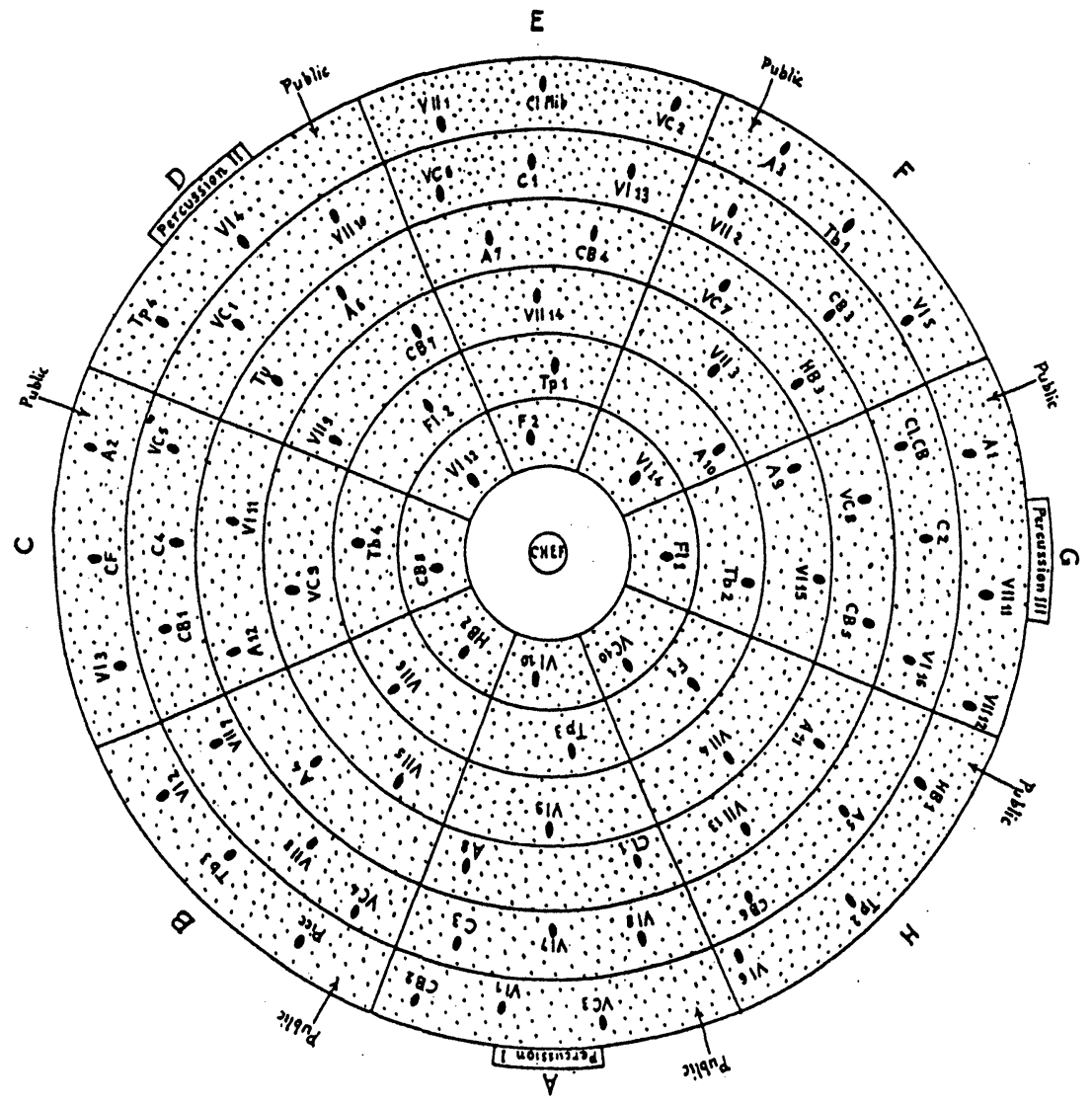

Example 5: The seating plan of Xenakis's Terrêtektorh.

(C) Salabert Editions, Paris. Used by permission.

The placement of the instruments and the successive entries of the brass at the beginning of Brant's composition are illustrated in Examples 3 and 4 respectively.

In Brant's "total antiphony" ensemble dispersion is linked to a variety of acoustic designs and compositional purposes, in addition to its function of reinforcing contrasts already present in the music and clarifying the work's collage-like texture. While Brant places the ensembles at various levels, in between and around the audience, Iannis Xenakis mixes the whole orchestra with the public. In two compositions from the late sixties, Nomos gamma (1967-68) 
and Terrêtektorh (1965-66), both for a large orchestra scattered among the audience (category Id) the auditory curtain which often separates the musicians from the public is completely removed.

In Terrêtektorh, for eighty-eight players dispersed among the audience, the musicians are stochastically distributed in a circular performance space (example 5). Here, according to the composer:

The orchestra is in the audience and the audience in the orchestra ... The scattering of the musicians brings in a radically new kinetic conception of music which no modern electro-acoustic means could match ... The musical composition will thereby be entirely enriched throughout the hall both in spatial dimension and in movement. The speeds and accelerations of the movement of the sounds will be realized, including logarithmic or Archimedean spirals in time and geometrically ... [with] ordered or disordered sonorous masses, rolling one against the other like waves. ${ }^{29}$

At the beginning of the work, one pitch $\left(\mathrm{e}^{4}\right)$ played by the strings, revolves around the circumference of the orchestra. A renotation of the score in a graphic form allows us to notice the various patterns of this movement (example 6). As can be seen, each rotation displays a particular outline of dynamic accents superimposed on its scheme of durations. At first, the motion is circular both in space (because of the position of the instruments) and in time (because of the constant velocity of the movement). Soon, the temporal pattern of dynamic accents changes, bringing in sound acceleration and deceleration, while the spatial form of the movement remains circular.

Xenakis's idea of immersing the listeners in the music results in a variety of the work's images perceived by individual listeners. The balance of soundmasses and the trajectories of sound movements, for instance, will seem different when perceived at a location next to a trombone at the circumference of the performance area than when heard at a location next to a flute, near the centre. The composition would, therefore, require repeated listenings from various points in space (the privileged placement of the conductor in the centre is obvious).

The audience is in the music, the music in the midst of the audience. In such cases, the composer is preoccupied with the auditory aspects of spatialization. In spatialized works with a symbolic content the signification of spatial shapes or

29 Iannis Xenakis, Formalized Music. Thought and Mathematics in Composition (Bloomington and London: Indiana University Press, 1971), 237, quoted by permission of the publisher. Chapters one to six were published in French as Musiques formelles (Paris: Editions Richard Masse, 1963). 


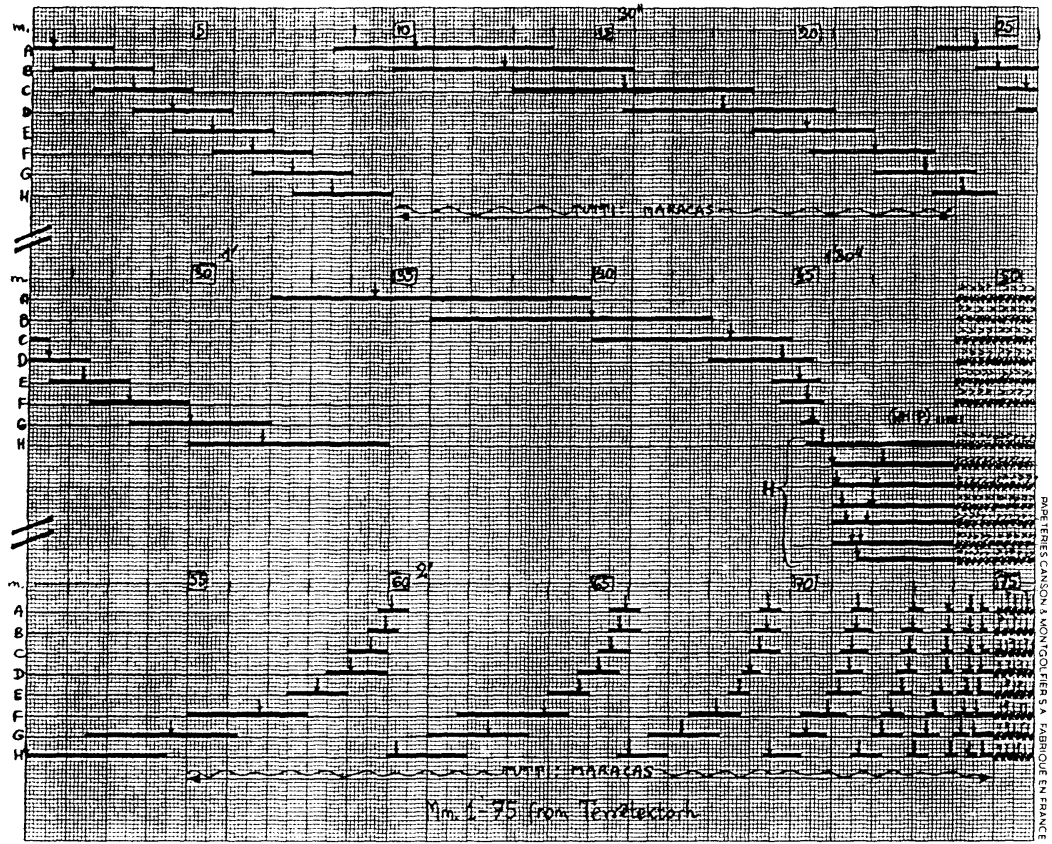

Example 6: A graph of mm. 1-75 of Terrêtektorh.

(C) Salabert Editions, Paris. Used by permission.

direction of movement becomes of primary importance. The listeners are expected to do more than listen to the music, they are invited to decipher the music's elaborate symbolism.

In John Tavener's Ultimos Ritos dedicated to St. John of the Cross (1972, category Ie), Christian symbolism is very rigorous. According to the composer, "the proportions of the work are those of a cross, and so is the layout of the choirs and some of the instruments." ${ }^{30}$ The symbolic shape of the cross, a standard floor plan in many churches, provides the basic architectural design for Ultimos Ritos (example 7). John Tavener writes:

Ideally, Ultimos Ritos should be performed in a cathedral or large church with gallery space. If performed elsewhere, it is essential that the building has a minimum of six seconds reverberation. ${ }^{31}$

30 John Taverner, Notes about Ultimos Ritos, unpublished typescript (1974), 1.

31 John Tavener, Ultimos Ritos. En Honor de San Juan de la Cruz (London: J \& W Chester Ltd., 1972). 


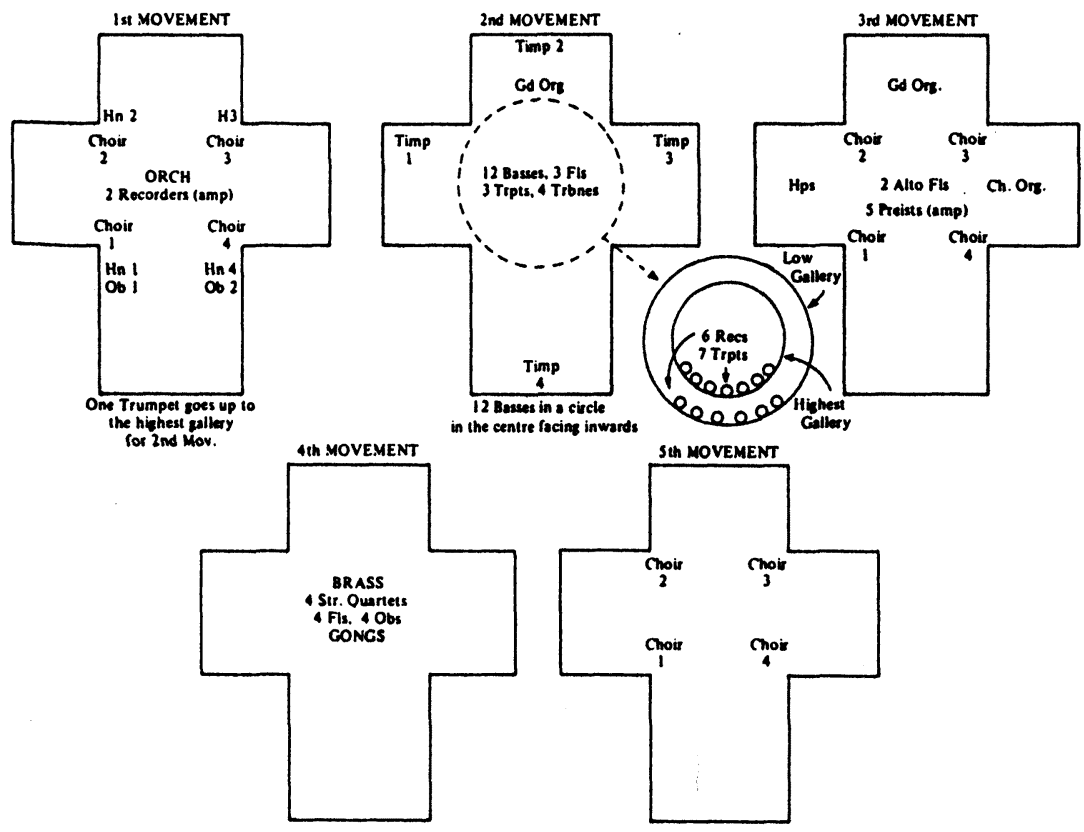

Example 7: The positions of the performers in Taverner's Ultimos Ritos.

(C) Chester Music Ltd., England. All rights for the U.S. and Canada controlled by G. Schirmer, Inc., New York (ASCAP). International copyright secured. All rights reserved. Used by permission.

This acoustic requirement is reflected in the score by frequent indications to "clear the sound" before proceeding with a subsequent section of the music (Ex. 8). The spatial elevation of the high-pitched and highly directional sounds of recorders and trumpets in the second movement seems to result from similar acoustic considerations. ${ }^{32}$ For Tavener, though, these are the instruments of "royalty and love" and their placement in the two high galleries represents the heavenly elevation of Christ descending to this Earth in the Eucharist.

32 The elevated spatial position of high-pitched sounds constitutes one of the basic premises of Henry Brant's idea of "total antiphony" and is realized in Voyage Four with the placement of the double basses in the audience and the flutes and soprano on the highest balcony (Henry Brant, "Space as an Essential Aspect of Musical Composition," in Contemporary Composers on Contemporary Music, ed. Elliott Schwartz and Barney Childs [New York: Holt, Rinehart and Winston, 1967]). 
28
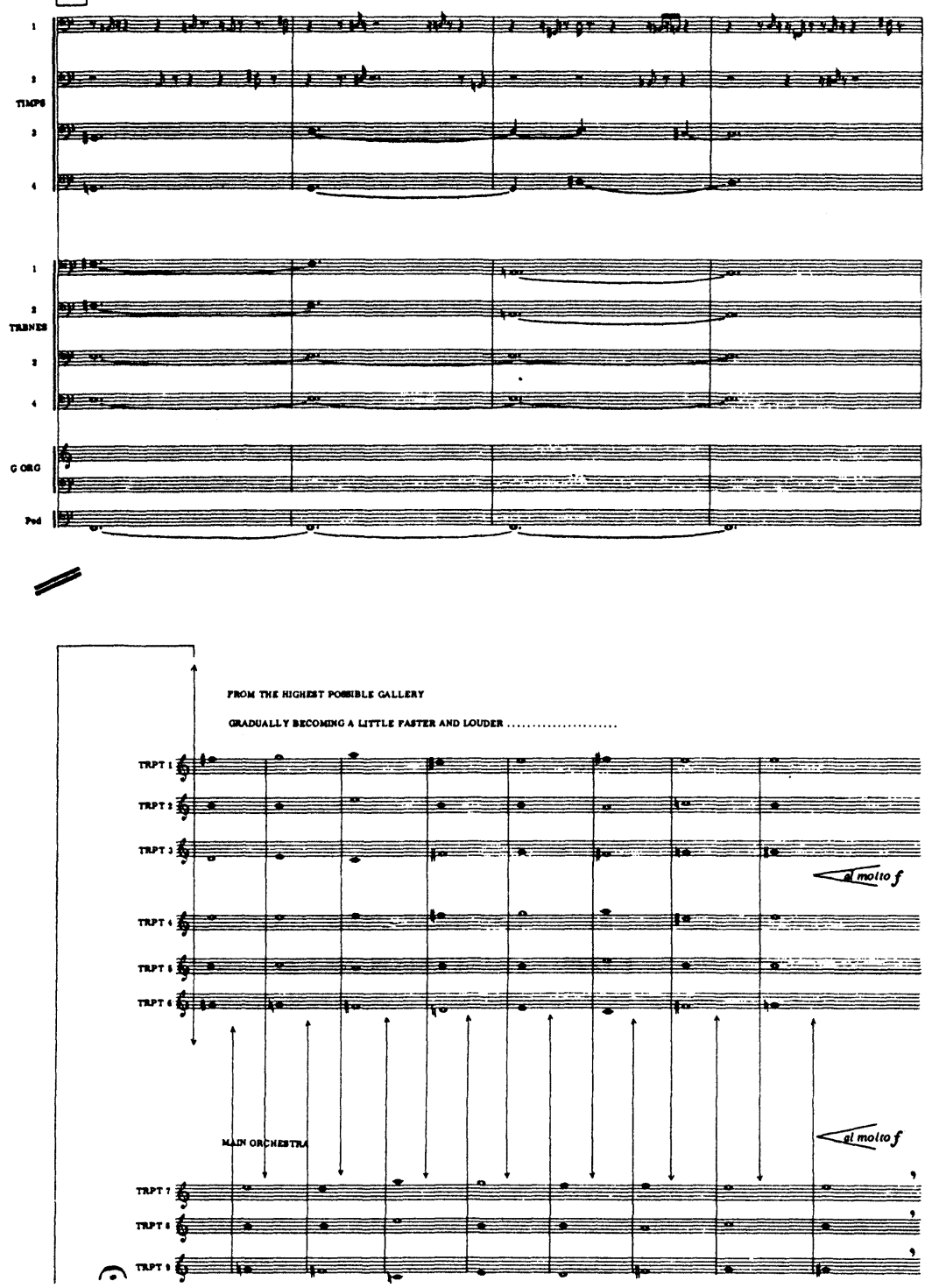

Example 8: "The descent of the Eucharist" in Ultimos Ritos, 67.

(c) Chester Music Ltd., England. All rights for the U.S. and Canada controlled by G. Schirmer, Inc., New York (ASCAP). International copyright secured. All rights reserved. Used by permission. 
The Eucharist "descends" in response to an ardent prayer by twelve basses, placed in a circle, chanting a poem by St. John of the Cross. The descent takes the form of an alternation between the elevated and floor-level instruments of the same timbre. Six trumpets (in the highest possible gallery surrounding the central cupola of the building) and six recorders (in a lower gallery) play a slow sequence of chords three times before it starts to resound from the ground (trumpets and flutes in the main orchestra directly below the cupola). These sections are interrupted by music from the timpani, trombones and organ, instruments which outline the shape of a cross on the horizontal plane. Example 8 presents one such intervention followed by the "descent," a dialogue of trumpets from high and low spatial locations. In Ultimos Ritos, theological statements are often expressed by symbolic geometric images; here - the interlocking designs of a vertical descent and a horizontal cross.

\section{Conclusions}

While following the trajectory "from point to sphere" we have discovered the richness of the spatial organization of sound in contemporary music, from simple textural differentiation through a variety of spatial designs. We have noticed that the role of spatial forms and characteristics is different in every composition. Various geometric shapes may be realized by the use of specific seating plans of performers or ensembles. Some of the spatial shapes can be endowed with a profound symbolic significance. In certain spatialized works, the fixed quasispatial structure of the composition can be limited to the specification of the acoustic conditions of its performance. Nevertheless, spatialization reveals itself primarily through the spatial quality of the music, through echoes, dialogues, sound movement, contrasts of volume, texture and direction.

One aspect of space, unrelated to "three-dimensional entities" of any kind, has not yet been mentioned. According to e. e. cummings,

the holy miraculous difference between

firstrate \& second implies nonth

inkable enormousness by con

trast with the tiny stumble from second to tenth rate $^{33}$

33 Excerpted from e.e. cummings, Complete Poems 1904-1962 (London: Liveright Publishing Corporation, c. 1958, 1986), reprinted with the permission of the publisher. 
The consideration of this "space" of the artistic quality of spatialized music is a topic for future investigation. Let us conclude this survey of spatialization by stating that the attractiveness of the idea of space in contemporary music is linked to the richness, strength and universality of the spatial organization of sound and the abundance of its symbolism. The spatiality of musical sound, now that it has been (re)discovered, is here to stay.

\begin{abstract}
In this study of spatial organization of sound, that is of "spatialization" in music, the term "spatial" refers to the three-dimensional performance space, not to pitch. "Spatialized music," distinct both from polychoral music and from musical theatre, means music with quasi-spatial structure defined by the composer in the score or in another medium of sound coding (digital or analog recording, specific software). Spatialization includes ensemble dispersion, movement of sounds, performers and audience, juxtaposition and interaction of real and virtual sound sources - every situation in which the position of the sound sources and the acoustic quality of the performance space are given compositional significance. A classification of spatial designs in music is followed by examples illustrating three aspects of spatialization: (1) the expression or simulation of geometrical patterns in music, (2) the movement of sound, (3) the symbolic function of spatial designs and movement. Musical examples and graphs of performer placement are taken from Henry Brant's Millenium II (1954), Karlheinz Stockhausen's Gruppen für drei Orchester (1955-57), Iannis Xenakis's Terrêtektorh (1965-66) and John Tavener's Ultimos Ritos (1972).
\end{abstract}

